Research Article

\title{
A Study on the Mechanism of Dynamic Pressure during the Combinatorial Key Strata Rock Column Instability in Shallow Multi-coal Seams
}

\author{
Jie Zhang $\mathbb{D}^{1,2}$ Bin Wang ${ }^{\mathbb{D}},{ }^{1}$ Wenyong Bai, ${ }^{1,3}$ and Sen Yang ${ }^{1,2}$ \\ ${ }^{1}$ School of Energy Engineering, Xi'an University of Science and Technology, Shaanxi, Xi'an 710054, China \\ ${ }^{2}$ Key Laboratory of Western Mine Exploitation and Hazard Prevention of Ministry of Education, \\ Xi'an University of Science and Technology, Shaanxi, Xi'an 710054, China \\ ${ }^{3}$ College of Coal Engineering, Shanxi Datong University, Datong 037000, China
}

Correspondence should be addressed to Bin Wang; wangbin1030@stu.xust.edu.cn

Received 23 December 2020; Accepted 6 February 2021; Published 3 March 2021

Academic Editor: Zhijie Wen

Copyright (c) 2021 Jie Zhang et al. This is an open access article distributed under the Creative Commons Attribution License, which permits unrestricted use, distribution, and reproduction in any medium, provided the original work is properly cited.

In order to study the pressure changes and support failure in mining face under concentrated coal pillar in shallow coal seam, the concentrated coal pillar in 30105 working face of Nan Liang Coal Mine was selected as the research object. In this study, the mechanism of dynamic mine pressure in mining face under concentrated coal pillar was investigated through multiple simulation experiments, numerical simulations, and theoretical analysis. The results of similar simulation experiment indicate that the dynamic mine pressure occurred at $25 \mathrm{~m}$ under the concentrated coal pillar and $7 \mathrm{~m}$ beyond the coal pillar. The strata roof was observed with sliding down, resulting in collapse and severe fractures commonly seen in rock column. The overlying strata caused the overall subsidence and collapse synchronously, resulting in the sudden increase of the resistance of the support in the working face, and the dynamic load coefficients reach 3.4 and 3.5. The theoretical analysis indicates that the two hard strata in the overlying strata of $3^{-1}$ coal meet the theoretical criterion of the combined key strata with the concentrated coal pillar of $2^{-2}$ coal in the weak interlayer of the combined key strata. The combined key strata bear the load of the whole overlying strata. The sliding instability featured with the rock column-type fracture located in the combined key strata is considered as the primary trigger of the abnormal resistance of the support and the dynamic mine pressure in the mining face under the concentrated coal pillar. The dynamic pressure model of "combination key strata-immediate roof-support" was established, along with the dynamic load coefficient calculation related to the rock column-type fracture and instability. The characteristics of dynamic load coefficient of the rock column-type fracture and instability under different overlying rock structure conditions were analyzed, providing references and insights into mining under similar geographic conditions.

\section{Introduction}

Yu Shen Fu Mine, as one of the major coal production sites in mainland China, is featured with coal seams shallowly buried in the loose and thick coal strata. The longwall mining conducted often leads to dynamic pressures, the cut-off of the overlaying rocks, and the gradient subsidence observed in the surface $[1,2]$. The roof is difficult to control. In order to avoid a series of issues aforementioned, room and pillar mining have been adopted $[3,4]$. In addition, the long wall spaced mining method was experimented in Nan Liang Mine to increase the mining efficiency [5], which left a large number of spaced coal pillars and dense coal pillars. As the mining deepens, the mining experiences of multiple excavation wells including those of Hao-Dang et al. [6] and Jin-Feng and $\mathrm{Xu}$ [7] well suggest that the remining coal pillars in the excavation zone of the upper coal seam pose as major safety threats to the lower coal seam. Jin-Feng et al. [8] considered the three-hinged arch structure of the overlaying strata beyond the coal pillar was the main cause of the instable pressure in the working face. De-Fu [9] 
studied the fracture of the roof overlaying strata where the spaced mining approach was adopted and concluded that the fracture of the roof overlaying strata in the Nan Liang site was featured with false roof, the collapse of the immediate roof, and the bending and subsidence of the primary roof with developed cracks in the middle. No gradient subsidence was observed in the surface. Zhang et al. [10] conducted research on the dynamic pressure zone of the dense coal pillar under the excavation where the room-and-pillar approach was adopted and concluded that the dynamic loads often occurred within the radius of 10 meters during the last pressure cycle before the exposure of the coal pillar. However, the researchers mainly focused on the structural instability of the coal pillar overlaying rock strata in the lower working face, the stability of the coal pillar, and loading zone featured with changes without looking into the load bearing structure of the overlaying strata and mechanism behind the dynamic pressure during the mining of the lower coal pillar.

In this study, the mining process of the concentrated coal pillar located in the upper coal seam in 30105 working face was studied focusing on the overlaying strata bearing structure and the collapse of the overlaying strata to analyze the mechanisms guiding the dynamic loading and pressure of the working face under the coal pillar, the sudden resistance increases, and drastic pressure increases.

\section{The Working Face Condition}

No. 30105 working face in Nan Liang Mine locates at $3^{-1}$ coal seam in the west side of the No. 301 mining zone, with a length of $2048 \mathrm{~m}$ and a slope length of $300 \mathrm{~m}$. The average coal seam is about $2.1 \mathrm{~m}$ with a slope between 0 and $3^{\circ}$. The coal seam contains a primary siltstone roof with a thickness of $20.4 \mathrm{~m}$, an immediate siltstone roof with a thickness between 0.5 and $3.7 \mathrm{~m}$, and a siltstone floor with a thickness of $7.4 \mathrm{~m}$. A distance between 25.7 and $35.2 \mathrm{~m}$ was identified from the No. 30105 working face to the No. 20109 and No. 20111 working face of $2^{-2}$ coal seam above. Due to different mining approaches and layout, the concentrated coal pillar left in the No. 20109 and No. 20111 working face of $2^{-2}$ coal seam is featured with an average width of $40 \mathrm{~m}$ and a length of $162 \mathrm{~m}$, which are about $485 \mathrm{~m}$ away from the center cut of No. 30105 working face. The layout of the $1^{\#} \sim 92^{\#}$ supports of No. 30105 working face is illustrated in Figure 1.

The mining of No. 30105 was mainly conducted through the coal pillar located in the overlaying excavation zone whose resistance carried by the working face supports was monitored in real time. According to the monitoring data, the upcoming loading distance was $22 \mathrm{~m}$. The average resistance on the support reached about $25.5 \mathrm{MPa}$ under zero load. Rib falls were observed among support $1^{\#} \sim 92^{\#}$ in the working face corresponding to the concentrated coal pillar during the loading cycle, with a $43 \%$ opening of the safety valve for the support. During the loading process, the support was compressed by $200 \sim 400 \mathrm{~mm}$, with a maximum load of $44.6 \mathrm{MPa}$ and a dynamic loading coefficient of 1.75 .

\section{The Collapse Simulation of the Overlaying Strata under the Concentrated Coal Pillar during the Mining}

3.1. The Experiment Design. In order to simulate the collapse of the overlaying strata of the concentrated coal pillar in the working face, a model was built following the scale of 1:100, as demonstrated in Figure 2, following the overlaying pillar layout of No. 30105 working face. The material adopted was mainly river sand with plaster and white power as the glue agents. The mica powder in 8 to 10 mesh was used to simulate the horizontal joints among the rock strata. Considering the height limitation of the model, the $17 \mathrm{~m}$ soil layer was replaced with a similar block made of iron. The dimension of the model was $3000 \mathrm{~mm}$ (length) $\times 1300 \mathrm{~mm}$ (height) $\times 200 \mathrm{~mm}$ (width). The dimension of the support was designed with a length of $200 \mathrm{~mm}$, a width of $35 \mathrm{~mm}$, and a lift range of 12 to $60 \mathrm{~mm}$, featured with thread rods following the scale of 1:100. The actual resistance on the support was converted by following the formula below, taking the scale of the model into consideration. The experiment was conducted in the following steps:

Step 1. A $10 \mathrm{~m}$ coal collar was preserved at the left boundary of the $2^{-2}$ coal seam, which was pushed froward by $50 \mathrm{~m}$ to form a spaced excavation zone. Another $40 \mathrm{~m}$ concentrated coal pillar was preserved which was pushed forward by $25 \mathrm{~m}$ to form a second knife-shaped working pillar.

Step 2. The excavation was conducted from left to the right in the $3^{-1}$ coal seam, aiming at similar migration and collapse pattern of the overlaying strata during the development of the concentrated coal pillar in the working face. The model after the completion of step 1 is demonstrated in Figure 3. The overlaying strata in the spaced excavation zone started to form a collapse in a gradient arch shape.

3.2. The Simulation Phenomenon and Result Analysis. The working face moved forward approaching the concentrated coal pillar, as shown in Figure 4(a). Cracks in the overlaying strata developed upward till $8 \mathrm{~m}$ into the red soil layer, without obvious surface subsidence. A gradient collapse zone was formed in the overlaying strata in the excavation zone, with a fracture angle of $68^{\circ}$. As the working face moved forward to $25 \mathrm{~m}$, as shown in Figure 4(b), the immediate roof collapsed, and the roof strata slid, resulting in major fractures and subsidence of the whole overlaying loose strata. Simultaneously, the resistance of the working face support was increased to $86.7 \mathrm{MPa}$ drastically with a dynamic loading coefficient of 3.4. A deep and through crack was developed along the coal wall of the working face until $13 \mathrm{~m}$ to $18 \mathrm{~m}$ into the coal pillar with a strata fracture angle of $70^{\circ}$. The working face continued to move forward, as shown in Figure 4(c) until the roof fell through the coal wall and the whole overlaying strata subsided. The crack, following the coal wall of the working face, developed through the edge of the coal pillar, the excavation roof, resulting in a through 


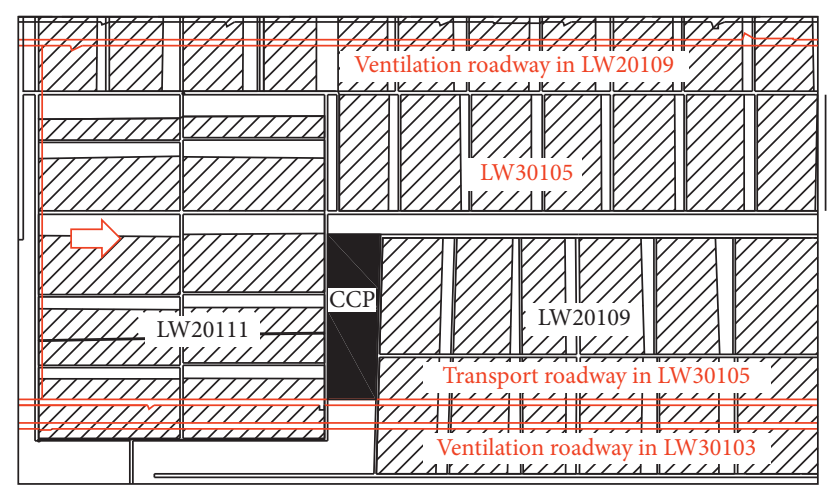

Figure 1: Layout of concentrated coal pillar in No.30105 working face.

\begin{tabular}{|c|c|c|c|}
\hline Lithology & Column & Thickness (m) & $\begin{array}{c}\text { KS } \\
\text { location }\end{array}$ \\
\hline Loess soil & & 34 & \\
\hline Red soil & & 43 & \\
\hline Mudstone & & 3.3 & \\
\hline Fine sandstone & & 2.2 & \\
\hline Siltstone & & 5.3 & \\
\hline Fine sandstone & & 4.6 & \\
\hline Siltstone & & 8.4 & KS1 \\
\hline $2^{-2}$ seam & & 2.0 & \\
\hline Mudstone & & 2.3 & \\
\hline Siltstone & & 4.6 & \\
\hline Siltstone & & 5.4 & \\
\hline Fine sandstone & & 6.0 & \\
\hline Siltstone & & 13 & KS2 \\
\hline Mudstone & & 0.7 & \\
\hline Siltstone & & 3.3 & \\
\hline Muddy siltstone & & 0.5 & \\
\hline $3^{-1}$ seam & & 3.5 & \\
\hline Siltstone & & 5.0 & \\
\hline
\end{tabular}

FIgURE 2: Column of overlying strata in No. 30105.

crack joining the ground. Simultaneously, the resistance of the working face support was increased to $89.25 \mathrm{MPa}$ drastically with a dynamic loading coefficient of 3.5. A gap was developed in the model surface with uneven subsidence and a strata fracture angle of $75^{\circ}$.

The analysis reveals that multiple dynamic loads occurred at the support during the mining process of the concentrated coal pillar in the working face, accompanied with the increased resistance in the support, which were

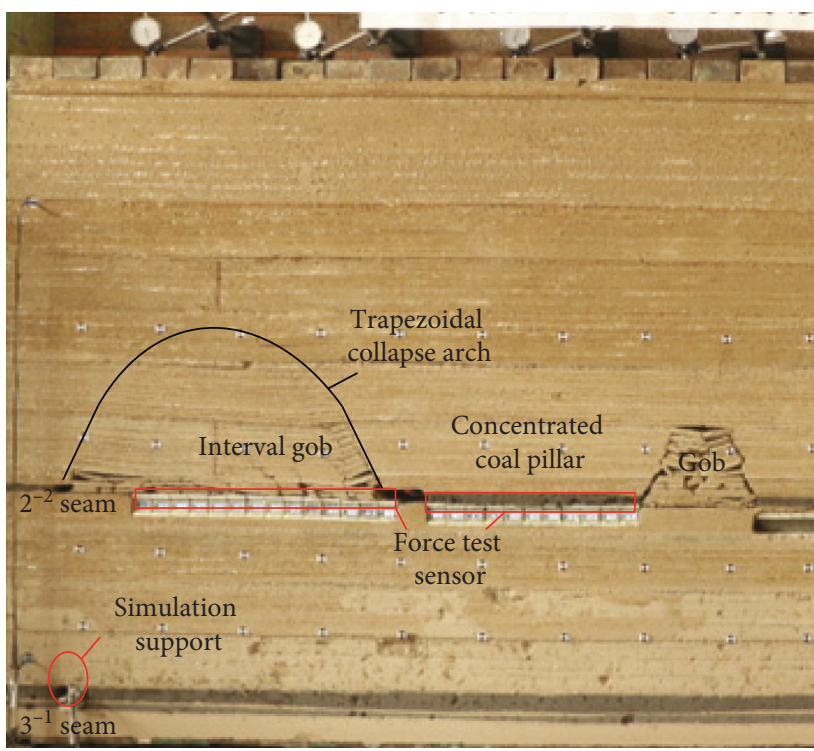

FIgURE 3: The characteristics of overburden collapse before working face entering coal pillar.

caused by the combinatorial key strata structure formed by two layers of hard overlaying strata as the carrier for the whole loose layer. When the suspension beam structure of the combinatorial strata formed due to the failure of the overlaying strata reaching the fracture limit, the combinatorial key strata structure experienced fractures and instability along the coal wall. Along with the fracture of the overlaying strata, the loose loading overlaying subsided, stressing the support and leading to drastic resistance on the hydraulic support. According to the resistance curve of the support in the model shown in Figure 5, two dynamic loading occurred to the working face due to the concentrated coal pillar, resulting in a greater resistance on the support than the rated resistance. The higher resistance on the support without the loading than that in the excavation zone suggests that the subsidence of the overlaying loose load bearing zone along with the combinatorial strata is the main cause of the drastic increase in the support resistance in the working face.

\section{The Mechanism behind the Instability and Rock Column-Type Fracture of the Key Combinatorial Strata}

4.1. The Parameter Analysis of the Key Combinatorial Strata. According to the combinatorial key strata theory [11] of the shallow coal seam, two hard strata layers of the shallowly buried coal seam with lose ground soil are considered as key strata. A sandwich structure is often formed with a weak stratum in between two hard strata, which move, deform, and fracture simultaneously. The sandwich structured strata share the common characteristics of key strata, such as the deformation, fracture, and support, despite of a greater thickness.

With the parameters of the overlaying strata of No. 30105 working face in the Nan Liang site, the fifth and 


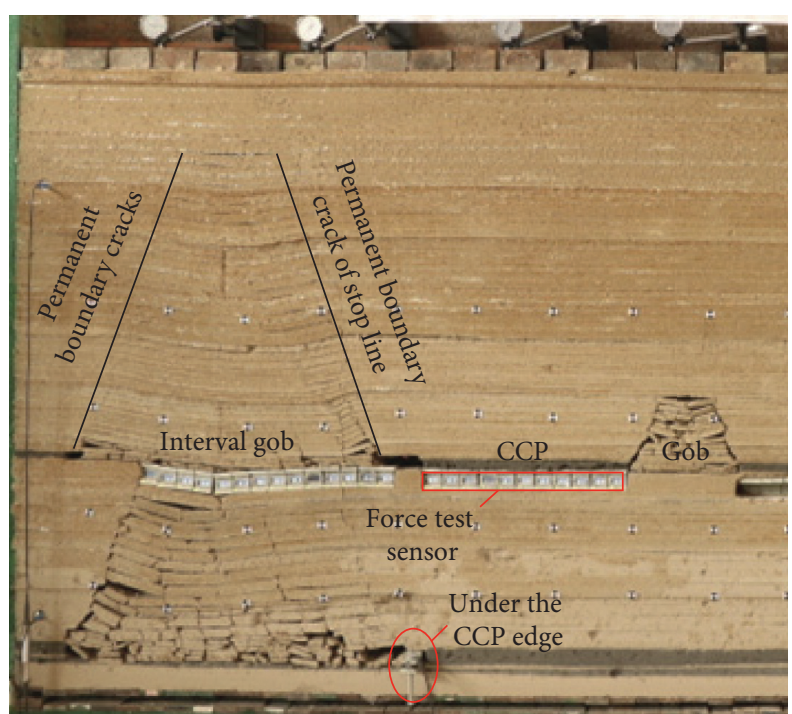

(a)

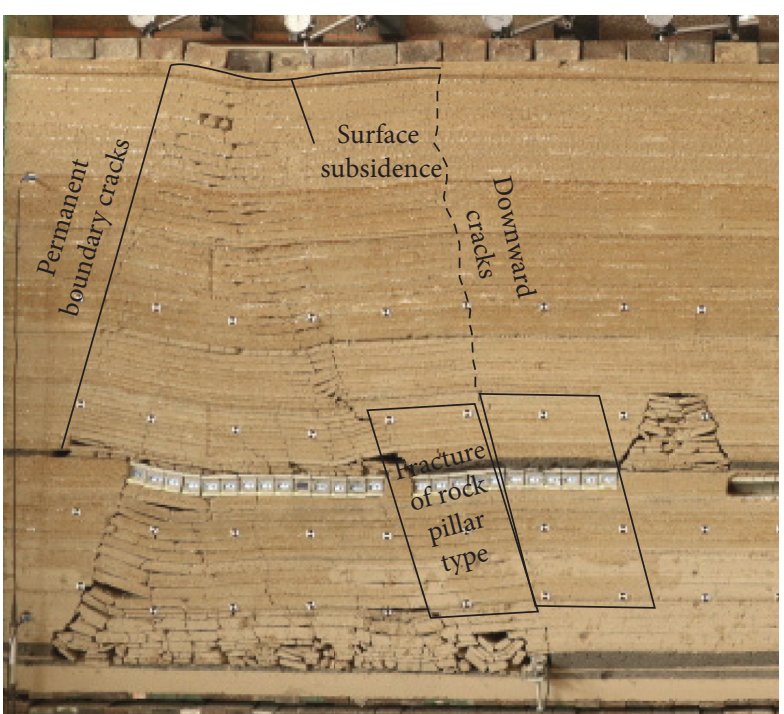

(b)

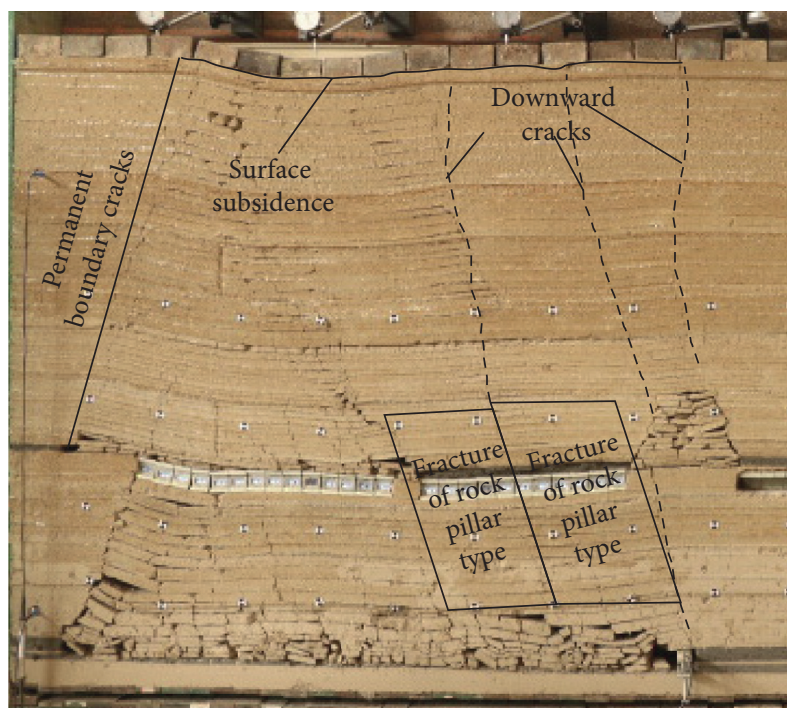

(c)

FiguRE 4: Collapse characteristics of overlying strata of concentrated coal pillar in working face. (a) Approaching the concentrated coal pillar. (b) $25 \mathrm{~m}$ under the concentrated coal pillar. (c) $7 \mathrm{~m}$ beyond the concentrated coal pillar.

eleventh strata layers above No. 30105 working face were evaluated based on the calculation formula (1) following the key strata theory [12] and the criterion of the combinatorial key strata.

$$
\frac{\sum_{i=1}^{n} \rho_{i} g h_{i} \cdot \sum_{i=n+1}^{m} E_{i} h_{i}^{3}}{\left(\sum_{i=n+1}^{m} \rho_{i} g h_{i}+q\right) \cdot \sum_{i=1}^{n} E_{i} h_{i}^{3}}=\frac{0.6277 \times 34305.51}{1.8533 \times 95270.78}=0.12<1 .
$$

According to the calculation, the fifth and eleventh strata layers above No. 30105 working face satisfy the criterion of the combinatorial key strata. The key parameters were calculated and provided below.

The thickness of the combinatorial key strata is $h_{z u}=44.5 m$

The loading of the combinatorial key strata is

$$
q_{z u}(x)_{m+1}=\frac{E_{z u} h_{z u}^{3}\left(\sum_{i=z}^{m} \rho_{i} g h_{i}+q\right)}{\sum_{i=z}^{m} E_{i} h_{i}^{3}}=2.48 \mathrm{MPa}
$$

The cyclic upcoming loading distance of the combinatorial key strata [13] $l_{\mathrm{zu}}$ is calculated by the following formula:

$$
l_{z u}=h_{z u} \sqrt{\frac{\sigma_{t} \psi}{3 q}}=44.5 \times \sqrt{\frac{2.5 \times 0.65}{3 \times 2.48}}=20.9 \mathrm{~m} .
$$

The tensile strength of the combinatorial key strata is $2.5 \mathrm{MPa}, \psi$ is 0.65 , referring to the impact coefficient of the layer number of the combinatorial key strata, and $q$ is 2.48 MPa, indicating the load of the loose layer.

According to the simulation demonstrated in Figure 4 and the theoretic analysis, a structural model simulating the 


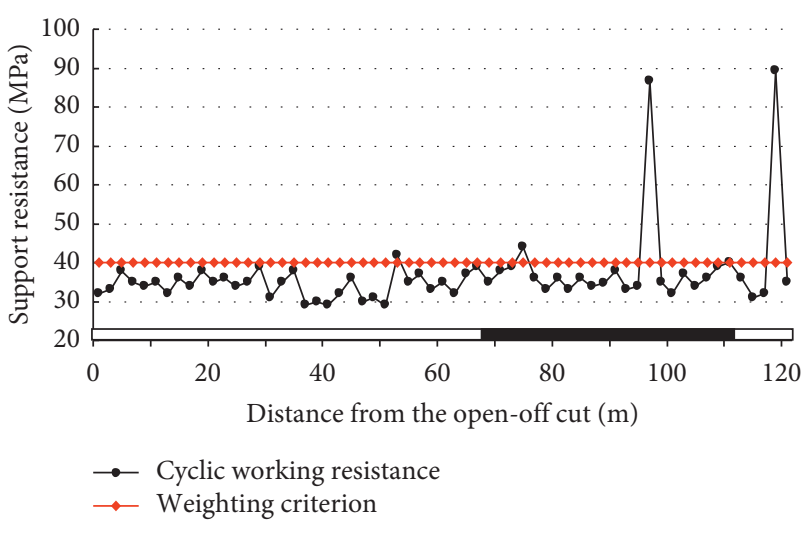

FIGURE 5: Resistance of support in simulated working face.

rock column-type fracture and instability of the combinatorial key strata in No. 30105 working face is established, as shown in Figure 6. B1 and B2 refer to the two layers of hard key strata above the working face, respectively. A relatively weaker layer was designed between two key strata layers. When the load was added, both key strata fractured simultaneously, resulting in major rock column-type fracture in the combinatorial key strata. $2^{-2}$ coal pillar located between the two key strata. During the mining underneath the coal pillar, due to the relatively great thickness of the fractured rock, the overlaying loading layer consequently fractured and subsided.

Based on the combinatorial key strata theory, to prevent the instability, collapse, and the sliding, the following condition has to be met [14]:

$$
T \tan \varphi \geq R_{A} .
$$

Substituting the pushing force $T$ imposed on the rock column, $R_{A}$ as the support force need to maintain stability and $l_{z u}$ as the rock column cyclic fracture distance, the following formula can be obtained:

$$
q \leq \frac{(2 \tan \varphi+3 \sin \alpha)^{2}\left[\sigma_{c}\right] \psi}{8 n} .
$$

In formula (5), $\tan \varphi$ refers to the friction among the rock columns, which was selected at $0.6,\left[\sigma_{c}\right]$ is the uniaxial compressive strength of the combinatorial key strata, and $n=10$, indicating the ratio between the compressive strength and the tensile strength of the combinatorial key strata.

The reverse angle of the fracture rock in the combinatorial key strata depends on the excavation height $M$, the thickness of the immediate roof $\Sigma h$, the crushing expansion coefficient $k_{p}$, and the length of the fractured rock column $l_{z u}$.

$$
\alpha^{\prime}=\arcsin \frac{M-\sum h\left(k_{p}-1\right)}{l_{\mathrm{zu}}} .
$$

With key parameters, the final reverse angle $\alpha^{\prime}=3.5^{\circ}$ following formula (6). Consequently, the following result can be obtained with formula (5):

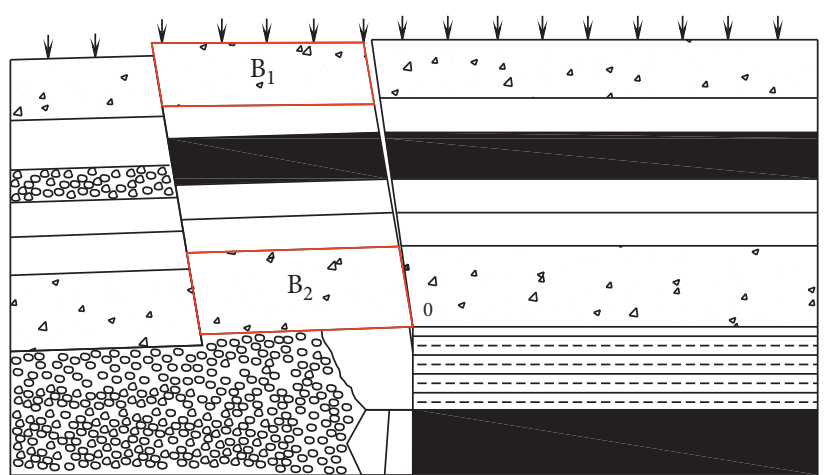

FIGURE 6: Fracture instability structure model of rock column in combination key strata.

$$
q \leq \frac{(1.2+3 \sin \alpha)^{2} \times 2.5 \times 0.65}{8}=0.38 \mathrm{MPa} .
$$

The comparison of formulae (7) and (2) has revealed that the actual loading on the combinatorial key strata was much higher than the maximum allowable loading without the fracture and instability. In other words, the fracture and instability of the combinatorial key strata is a major cause of the drastic changes to the pressure of the working face under the concentrated coal pillar in the shallow coal seam.

\subsection{The Dynamic Pressure Mechanism behind the Pillar-Type Fracture and Instability}

4.2.1. The Dynamic Loading Model Featured with the Combinatorial Key Strata-The Immediate Roof-the Support. According to the model built to simulate the rock columntype fracture and instability of the combinatorial key strata, a loading dynamic model featured with a system of "the combinatorial key strata-the immediate roof-the support" is established, as shown in Figure 7. In order to simplify the loading calculation during the rock column-type fracture, assume that the fractured rock column B of the combinatorial key strata (whose weight is represented with $G_{z u}$ ) slid and fractured at the $\Delta h$ from the immediate roof and consequently landed on the immediate roof. The immediate roof was pushed down by $\Delta h_{z}$. During the sliding, the following assumptions were made:

(1) No deformation occurs to the two key strata and no rebound occurs after the fractured rock contacts the immediate roof.

(2) The immediate roof still follows Hooke's law after the deformation.

(3) The acoustic, heat, and radiant energy generated during the sliding and instability can be overlooked [15].

According to the above assumptions, during the fracture, sliding, and instability of the combinatorial rock column, the lower boundary of the immediate roof reaches the lowest position when the velocity of the fractured rock column becomes zero after contacting with the immediate roof. 


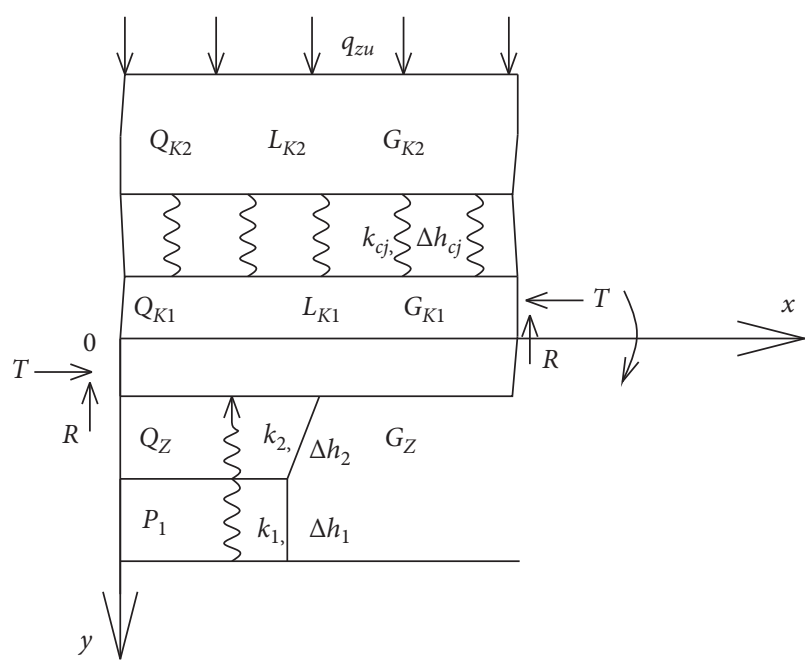

FIGURE 7: Mechanical model of fracture columns in combination key strata.

Meanwhile, the maximum sinking of the immediate roof is $\Delta h_{z}$, and the corresponding dynamic load is $F_{d z}$, the sinking distance of the fractured rock column is $\Delta h+\Delta h_{z}$, which is the work done by the frictional force $f$ on both sides of the fractured rock column during the failure $2 f\left(\Delta h+\Delta h_{z}\right)$.

Under the evenly distributed loading, the thickness of the combinatorial key strata $h_{z u}=h_{k 1}+h_{k 2}+h_{c j}$. However, with the coal pillar as the middle layer of the combinatorial key strata, local damages have been formed due to the excavation zones at both sides, resulting in statistic loading compression $\Delta h_{c j}$ under the stress from the coal pillar. Therefore, the actual thickness during the fracture, sliding, and instability of the combinatorial rock column can be expressed by the following formula:

$$
h_{z u}=h_{k 1}+h_{k 2}+h_{c j}-\Delta h_{c j} .
$$

The elastic energy accumulated inside the interlayer rock layer can be expressed by the following formula:

$$
U_{\mathrm{zu}}=\frac{1}{2} k_{c j} \Delta h_{\mathrm{cj}}^{2}
$$

According to the law of conservation of mechanical energy, the kinetic energy $E_{k \_z u}$, potential energy $E_{p \_z u}$, and elastic accumulation energy $U_{z u}$ during the instability of the fractured rock column are transformed into the work done by overcoming the frictional force on both sides of the fractured rock column into the added strain energy $V_{\varepsilon_{-}} z^{\circ}$ from the immediate roof to the support.

$$
E_{k_{-} \mathrm{zu}}+E_{p_{-} \mathrm{zu}}-2 f \cdot\left(\Delta h_{z}+\Delta h\right)=V_{\varepsilon_{-} z} .
$$

According to the collapse characteristics of the fractured rock column of the combinatorial key layer, the overlying load layer of the combined key layer and the failure of the fractured rock column shall occur simultaneously during the roof cutting of the fractured rock column. Therefore, when the rock column collapses and moves to the lowest end, the total potential energy of the combined key layer can be calculated following the formula below:

$$
E_{p_{-} z u}=\left(G_{z u}+q_{z u}\right)\left(\Delta h_{z}+\Delta h\right)+\frac{1}{2} k_{c j} \Delta h_{c j}^{2} .
$$

Considering that initial velocity and final velocity of the fractured rock pillar are both zero,

$$
E_{k_{-} z u}=0 \text {. }
$$

The work done by the fractured rock column to overcome friction

$$
W_{f}=2 \frac{\mu q_{z u} l_{k}^{2}}{8 h}\left(\Delta h_{z}+\Delta h\right)
$$

$T$ : The horizontal push force imposed on the fractured rock column $T=q_{z u} l_{k}^{2} / 8 h$

$\mu$ : Friction coefficient in vertical direction of rock column

a: Length of contact surface of fractured rock column $\Delta h_{z}$ : Static displacement of the immediate roof.

Due to material complying with Hooke's law, the strain energy added by the direct top is equal to the work done by the dynamic load $F_{d z}$ on the displacement, as shown in the following formula:

$$
V_{\varepsilon_{-} z}=\frac{1}{2} F_{d z} \cdot \Delta h_{z}
$$

For the immediate roof, the relationship between $F_{d z}$ and $\Delta h_{z}$ can be described as follows:

$$
F_{d z}=\frac{E_{z} A}{\sum h} \Delta h_{z}
$$

Substituting (15) into formula (14), the following formula is obtained:

$$
V_{\varepsilon_{-} z}=\frac{1}{2} \frac{E_{z} A}{\sum h} \cdot \Delta h_{z}^{2}
$$

$E_{z}$ refers to the elastic modulus of the immediate roof; $A$ refers to the contact area of the immediate roof. Substituting (11), (12), and (13) into formula (10), the following formula is obtained:

$$
\left(G_{z u}+q_{z u}\right)\left(\Delta h_{z}+\Delta h\right)+\frac{1}{2} k_{c j} \Delta h_{z u}^{2}=2 \frac{\mu q_{z u} l_{k}^{2}}{8 h} \cdot\left(\Delta h_{z}+\Delta h\right)+\frac{1}{2} \frac{E_{z} A}{\sum h} \cdot \Delta h_{u}^{2} .
$$

Considering that the weight of the second layer of the key strata and the stress of the concentrated coal pillar as the static load, the compressive displacement of the fractured strata of the combinatorial key strata is calculated according to the following formula:

$$
\Delta h_{z u}=\frac{\left(G_{z u}+q_{z u}\right) h_{c j}}{E_{c j} A} .
$$

In formula (18), $\left(G_{k 2}+q_{z u}\right)=\left(E_{c j} A / h_{c j}\right) \Delta h_{c j}$.

Considering the first layer of the key strata as the static load on the immediate roof, the static compression of the immediate roof is 


$$
\Delta_{z}=\frac{\left(G_{z u}+q_{z u}\right) \sum h}{E_{z} A}
$$

In formula (19),

$$
G_{z u}+q_{z u}=\frac{E_{z} A}{\sum h} \Delta_{z}
$$

Therefore, formula (13) can be written as

$$
\begin{gathered}
\frac{E_{z} A}{\sum h} \Delta_{z}\left(\Delta h_{z}+\Delta h\right)+\frac{1}{2} k_{c j} \Delta h_{c j}^{2}=2 \frac{\mu q_{z u} l_{z}^{2}}{8 h} \cdot\left(\Delta h_{z}+\Delta h\right)+\frac{1}{2} \frac{E_{z} A}{\sum h} \Delta h_{z}^{2}, \\
\frac{1}{2} \frac{E_{z} A}{\sum h} \Delta h_{z}^{2}+\left(2 \frac{\mu q_{z u} l_{k}^{2}}{8 h}-\frac{E_{z} A}{\sum h} \Delta_{z}\right) \cdot \Delta h_{z}+\left(2 \frac{\mu q_{z u} l_{k}^{2}}{8 h}-\frac{E_{z} A}{\sum h} \Delta_{z}\right) \Delta h-\frac{1}{2} k_{c j} \Delta h_{c j}^{2}=0 .
\end{gathered}
$$

Therefore, the above formula (17) can be solved with two roots for $\Delta h_{z}$, and the root greater than $\Delta z$ is taken to obtain the formula below:

$\Delta h_{z}=\frac{-\left(2\left(\mu q_{z u} l_{k}^{2} / 8 h\right)-\left(E_{z} A / \sum h\right) \Delta_{z}\right)+\sqrt{\left(2\left(\mu q_{z u} l_{k}^{2} / 8 h\right)-\left(E_{z} A / \sum h\right) \Delta_{z}\right)^{2}-4(1 / 2)\left(E_{z} A / \sum h\right)\left[\left(2\left(\mu q_{z u} l_{k}^{2} / 8 h\right)-\left(E_{z} A / \sum h\right) \Delta_{z}\right) \Delta h-(1 / 2) k_{c j} \Delta h_{c j}^{2}\right]} .}{2(1 / 2)\left(E_{z} A / \sum h\right)}$.

The stiffness of the immediate roof $k_{2}=E_{z} A / \sum h$ :

$$
\begin{aligned}
& \Delta h_{z}=\frac{-\left(2 f-k_{2} \Delta_{z}\right)+\sqrt{\left(2 f-k_{2} \Delta_{z}\right)^{2}-2 k_{2}\left[\left(f-k_{2} \Delta_{z}\right) \Delta h-(1 / 2) k_{c j} \Delta h_{c j}^{2}\right]}}{k_{2}}, \\
& \Delta h_{z}=\Delta_{z} \cdot\left(1-\frac{2 f}{k_{2} \Delta_{z}}+\sqrt{\left.\left(\frac{2 f}{k_{2} \Delta_{z}}-1\right)\left(\frac{2 f}{k_{2} \Delta_{z}}-1-\frac{2 \Delta h}{\Delta_{z}}\right)+\frac{k_{c j} \Delta h_{c j}^{2}}{k_{2} \Delta_{z}^{2}}\right)},\right. \\
& F_{d z}=\frac{E_{z} A}{\sum h} \cdot \Delta_{z} \cdot\left(1-\frac{2 f}{k_{2} \Delta_{z}}+\sqrt{\left(\frac{2 f}{k_{2} \Delta_{z}}-1\right)\left(\frac{2 f}{k_{2} \Delta_{z}}-1-\frac{2 \Delta h}{\Delta_{z}}\right)+\frac{k_{c j} \Delta h_{c j}^{2}}{k_{2} \Delta_{z}^{2}}}\right), \\
& F_{d z}=\left(G_{z u}+q_{z u}\right) \cdot K_{d}, \\
& K_{d}=1-\frac{2 f}{k_{2} \Delta_{z}}+\sqrt{\left(\frac{2 f}{k_{2} \Delta_{z}}-1\right)\left(\frac{2 f}{k_{2} \Delta_{z}}-1-\frac{2 \Delta h}{\Delta_{z}}\right)+\frac{k_{c j} \Delta h_{c j}^{2}}{k_{2} \Delta_{z}^{2}} .}
\end{aligned}
$$

According to formula (25), the loading coefficient $K_{d}$ mainly depends on the friction $f$ at both ends of the fractured rock, the stiffness $k_{2}$ of the immediate roof, the static compression of the immediate roof $\Delta_{z}$, the gap between the primary roof and the immediate roof $\Delta h$, the static compression of the intermediate strata $\Delta h_{c j}$, and the stiffness of the intermediate strata $k_{c j}$.

\subsubsection{The Discussion of Loading Coefficient}

(1) When the friction at both ends of the fractured rock column is overlooked, namely, $f=0$.

(1) Under the circumstance of single key strata in the overlaying strata during the mining of the single coal seam, the loading coefficient is 


$$
K_{d}=1+\sqrt{1+\frac{2 \Delta h}{\Delta_{z}}}
$$

When no gap is identified between the key strata and the immediate roof, namely, $\Delta h=0, K_{d}=2$.

(2) Repeated mining was conducted to the coal seam and the upper coal seam was excavated (the key strata of the upper coal seam was fractured),

$$
K_{d}=1+\sqrt{1+\frac{2 \Delta h}{\Delta_{z}}+\frac{k_{c j} \Delta h_{c j}^{2}}{k_{2} \Delta_{z}^{2}}} .
$$

When no gap is identified between the key strata and the immediate roof, namely, $\triangle h=0$,

$$
K_{d}=1+\sqrt{1+\frac{k_{c j} \Delta h_{c j}^{2}}{k_{2} \Delta_{z}^{2}}}
$$

(3) The overlaying strata of the shallow coal seam meet the criterion of the key combinatorial key strata structure; the combinatorial key strata experience the collapse and the instability.

When there is no static compression in the middle layer between two key hard strata, namely, $\Delta h_{c j}=0$, the loading coefficient can be expressed in formula (26).

When the static compression in the middle layer between two key hard strata, namely, $\Delta h_{c j} \neq 0$, the loading coefficient can be expressed in formula (27). Assuming that the stiffness of the middle layer is $i$ times of the stiffness of the immediate roof, $k_{c j}=i k_{2}$, $(i>0)$ in formula (27).

$$
K_{d}=1+\sqrt{1+\frac{2 \Delta h}{\Delta_{z}}+\left[\frac{i\left(G_{k 2}+q_{z u}\right) h_{c j}}{\left(G_{z u}+q_{z u}\right) \sum h}\right]^{2}}
$$

In formula (29), whereas $\Delta h \neq 0$ indicates that gap exists between the combinatorial key strata and the immediate roof, the sudden compression of the immediate roof can be considered as a multiple of the static load compression and the dynamic load factor increases exponentially.

When $\Delta h=0$ indicating no gap exists between the primary roof and the immediate roof, the dynamic load coefficient is illustrated in formula (28) below.

(2) When $2 f=k_{2} \Delta_{z}$,

$$
K_{d}=\sqrt{\frac{k_{c j} \Delta h_{c j}^{2}}{k_{2} \Delta_{z}^{2}}}
$$

The static load leading to the rock column-type fracture of the combinatorial key strata originates from the static resilient energy and resilient energy released instantly from the immediate roof during the fracture, resulting in loading shock to the support of the working face. In addition, during the rock column-type fracture of the combinational key strata, even with the maximum friction at both ends of the rock column, the sliding and instability of the fractured rock column still produces a high loading shock to the working face.

Based on the analysis above and the structure of the combinatorial key strata in No. 30105 working face in Nan Liang Mine, as well as the pressure monitoring, no gas was identified between the primary roof and the immediate roof, namely, $\Delta h=0$, the loading coefficient can be calculated by the following formula to obtain

$$
K_{d}=1+\sqrt{1+\left[\frac{i\left(G_{k 2}+q_{z u}\right) h_{c j}}{\left(G_{z u}+q_{z u}\right) \sum h}\right]^{2}}=3.64
$$

In formula (31),

$$
\left[\frac{\left(G_{k 2}+q_{z u}\right) h_{c j}}{\left(G_{z u}+q_{z u}\right) \sum h}\right]^{2}=\left(\frac{1.85 \times 13.2}{2.48 \times 4}\right)^{2}=6 .
$$

4.2.3. The Loading Analysis of the Support. Based on the stability analysis of the fractured strata in the combinatorial key strata, as shown in Figure 5, the moment above the support of the working face $\sum M_{o}=0$;

$$
\begin{aligned}
& T(h-a-w)+\mathrm{Tl} \tan \phi-\left(G_{z u}+q_{z u}\right) \frac{l}{2}=0, \\
& a=\frac{1}{2}\left(h-\frac{1}{2} l \sin \alpha\right) .
\end{aligned}
$$

The following formula can be obtained:

$$
\begin{aligned}
& T=\frac{l\left(G_{z u}+q_{z u}\right)}{2(h-a-w+l \tan \phi)}, \\
& T=\frac{G_{z u}+q_{z u}}{i+0.5 \sin \alpha-2 \sin \alpha_{\max }+2 \tan \phi},
\end{aligned}
$$

where $G_{z u}$ refers to the weight of the combinatorial key strata; $q_{z u}$ indicates the loading effect of the loose layer on the combinatorial key strata.

The supporting force $R_{A}$ to prevent the sliding and instability of the combinatorial key strata can be calculated based on Figure 5.

$$
\begin{aligned}
& R_{A}+2 T \tan \varphi \geq G_{z u}+q_{z u}, \\
& R_{A} \geq\left(G_{z u}+q_{z u}\right)\left(1-\frac{2 \tan \phi}{i+0.5 \sin \alpha-2 \sin \alpha_{\max }+2 \tan \phi}\right) .
\end{aligned}
$$

According to formula (17), the reverse angle of the fracture rock was calculated, where $\alpha^{\prime}=3.5^{\circ}, \tan \phi=0.6$, and $i=2.1$. 
TABLE 1: Rock mechanical parameters in numerical simulation.

\begin{tabular}{|c|c|c|c|c|c|c|c|c|c|c|}
\hline \multirow[b]{2}{*}{ Lithology } & \multirow[b]{2}{*}{ Thickness (m) } & \multicolumn{5}{|c|}{ Material properties of rock layers } & \multicolumn{4}{|c|}{ Joint properties of rock layers } \\
\hline & & $\rho \mathrm{kN}\left(\mathrm{m}^{3}\right)$ & $\mathrm{K}(\mathrm{GPa})$ & $\mathrm{G}(\mathrm{GPa})$ & $\mathrm{C}(\mathrm{MPa})$ & $\varphi\left({ }^{\circ}\right)$ & $\sigma \mathrm{T}(\mathrm{MPa})$ & $\mathrm{Kn}(\mathrm{GPa})$ & $\mathrm{Ks}(\mathrm{GPa})$ & $\varphi\left({ }^{\circ}\right)$ \\
\hline Loess soil & 34 & 1800 & 3.1 & 1.78 & 0.06 & 12 & 0.04 & 3.6 & 2.2 & 5 \\
\hline Red soil & 43 & 1800 & 3.1 & 1.78 & 0.06 & 12 & 0.04 & 3.6 & 2.2 & 5 \\
\hline Bedrock & 6 & 2400 & 8.3 & 5.4 & 0.9 & 30 & 0.6 & 6.2 & 4.3 & 15 \\
\hline Basic roof & 8 & 2550 & 10.5 & 7.4 & 2.2 & 38 & 0.7 & 9.4 & 6.3 & 30 \\
\hline Immediate roof & 2 & 2400 & 6.8 & 3.9 & 0.6 & 30 & 0.44 & 5.4 & 3.5 & 15 \\
\hline No. $2^{-2}$ seam & 2 & 1300 & 5.7 & 3.2 & 0.4 & 25 & 0.5 & 4.8 & 3.3 & 20 \\
\hline Bedrock & 20 & 2400 & 8.9 & 6.2 & 0.9 & 30 & 0.6 & 8.4 & 5.1 & 15 \\
\hline Basic roof & 8 & 2550 & 12.5 & 8.4 & 2.2 & 38 & 0.7 & 9.4 & 6.3 & 30 \\
\hline Immediate roof & 4 & 2450 & 6.5 & 3.9 & 0.6 & 30 & 0.44 & 5.4 & 3.5 & 15 \\
\hline No. $3^{-1}$ seam & 2 & 1350 & 5.7 & 3.5 & 0.4 & 25 & 0.5 & 4.8 & 3.3 & 20 \\
\hline Floor strata & 16 & 2500 & 10.33 & 8.17 & 0.9 & 30 & 0.6 & 8.4 & 5.1 & 15 \\
\hline
\end{tabular}

$$
R_{A} \geq 0.625 \times\left(G_{z u}+q_{z u}\right) .
$$

The weight of the combinatorial key strata $G_{z u}$ and the weight of the loading layer $q_{z u}$ are calculated as follows:

$$
\begin{aligned}
G_{z u} & =\sum h_{z u} \rho_{z u} g l_{z u}=20461 \mathrm{kN}, \\
q_{z u} & =\xi \sum h_{s} \rho_{s} g l_{z u}=7724 \mathrm{kN},
\end{aligned}
$$

where $\sum h_{z u}=44.5 \mathrm{~m} ; \rho_{z u} g=0.022 \mathrm{MN} / \mathrm{m}^{3} ; l_{z u}=20.9 \mathrm{~m}$; $\sum h_{s}=77 \mathrm{~m} ; \rho_{s} g=0.016 \mathrm{MN} / \mathrm{m}^{3}$; and

$\xi$ refers to the load transfer coefficient, which was selected at 0.3 based on the simulation.

$$
R_{A} \geq 0.625 \times\left(G_{z u}+q_{z u}\right)=17615 \mathrm{kN} .
$$

Considering that during the rock column of the combinatorial key strata slipping and falling, the support force on the working face includes the weight of the immediate roof and the load transmitted by the fractured rock column of the combined key layer, the working force of the support should be

$$
\begin{aligned}
& P=\left(G_{z h}+R_{A}\right) b, \\
& P=\left(G_{z h}+R_{A}\right) b=31666 \mathrm{kN},
\end{aligned}
$$

where $G_{z h}$ refers to the weight of the immediate roof strata

$$
G_{z h}=\sum h_{z h} \rho_{z h} g l_{k}=480 \mathrm{kN}
$$

where $b$ refers to the width of the support, $L_{k}$ is the control distance at $50 \mathrm{~m}, \Sigma h_{z h}$ indicates the thickness of the immediate roof at $4 \mathrm{~m}$, and $\rho_{z h}$ gsuggests the visual density of the immediate roof at $0.024 \mathrm{MN} / \mathrm{m}^{3}$.

Based on the existing hydraulic support (model ZY9000/ 14/26D) installed in No. 30105 working face in Nan Laing Mine, in order to prevent the coal pillar lower roof sliding and instability during the cyclic loading, the required load capacity is estimated at $31666 \mathrm{kN}$, which is 3.51 times of the rating resistance of the existing support, which also explains the drastic changes to the cyclic pressure of the working face and the opening of the safety valve for the hydraulic support.

4.2.4. The Numerical Verification. In order to verify the accuracy of the analysis above, the discrete element UDEC software was used to establish a model to simulate and analyze

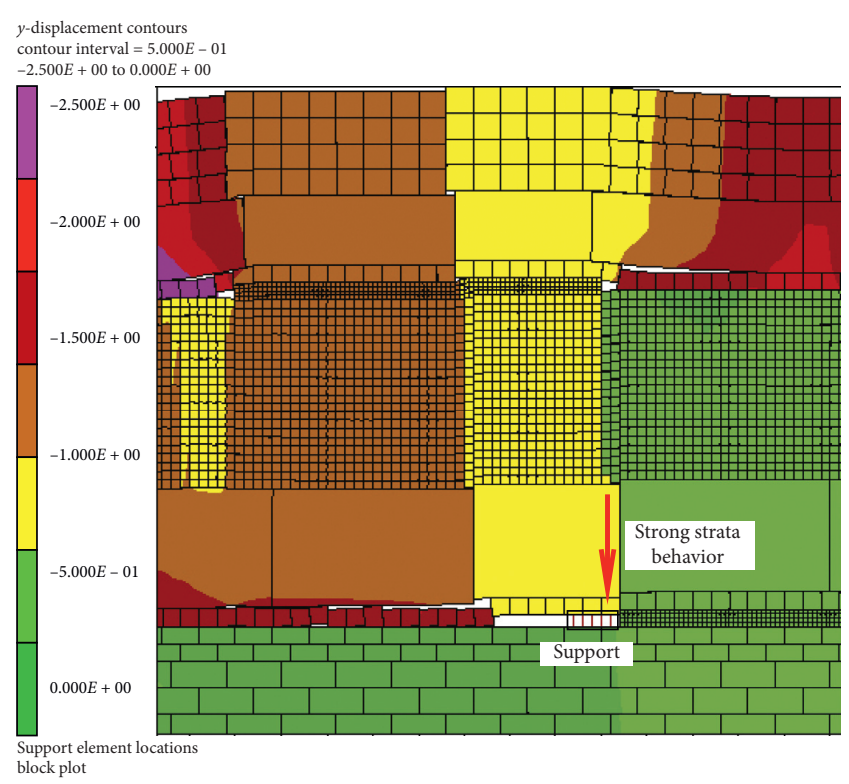

FIGURE 8: $y$-displacement contours under concentrated coal pillar.

the reasons for dynamic pressure in mining under a concentrated coal pillar. The model is appropriately simplified on the basis of the column diagram of Figure 2 and the numerical calculation model is established with a length of $180 \mathrm{~m}$ and a height of $100 \mathrm{~m}$. An evenly distributed load of $0.9 \mathrm{MPa}$ was applied to the upper surface of the model to replace the $50 \mathrm{~m}$ thick loose layer. The horizontal and vertical movement were restricted via setting the boundary limits with the upper boundary set as a free boundary. The model block adopts the Mohr-Coulomb model, and the joint model adopts the joint surface contact Coulomb slip model. The mechanical parameters of coal strata are shown in Table 1.

After the model was built, based on the actual mining conditions, a length of $50 \mathrm{~m}$ was excavated at both sides of the coal pillar to simulate the spaced structure of the overlaying strata in the field. $3^{-1}$ coal was mined from the left to the right. The vertical displacement under the coal pillar in the working face during the mining can be seen in Figure 8, which suggests that the shear instability occurred at $26 \mathrm{~m}$ under the coal pillar and $3 \mathrm{~m}$ in the coal pillar, with a roof cutting height of $0.5 \mathrm{~m}$. The hydramulic support in the working face was simulated with the tool "SUPPORT"in the software. The support load 


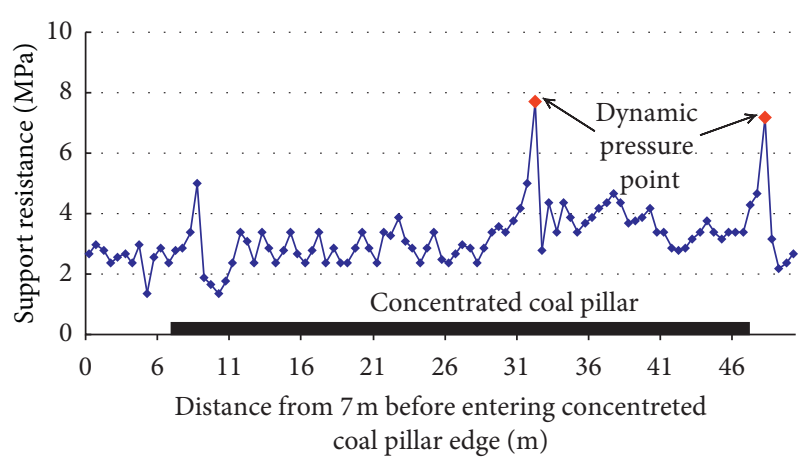

Figure 9: The variance curve of the support resistance.

curve was demonstrated in Figure 9. The support resistance under the coal pillar increased consistently, with local maximum resistance of $8.7 \mathrm{MPa}$ and a loading efficient of 3.34 , which is consistent with the calculation.

\section{Conclusion}

(1) According to the evaluation criterion of the combinatorial key strata, two upper key strata in No. 30105 working face are deemed as the combinatorial key strata. $2^{-2}$ concentrated coal pillar is located between two key strata. The combinatorial key strata bear the whole overlaying strata and loose strata layer. The sliding and instability of the combinatorial key strata is the root cause of drastic changes to the mining pressure of the working face in the shallow coal during the excavation under the concentrated coal pillar.

(2) According to the simulation, loading occurred at $25 \mathrm{~m}$ under the coal pillar and $7 \mathrm{~m}$ beyond the coal pillar in the working face. The loading distance was $20 \mathrm{~m}$ and $22 \mathrm{~m}$, respectively, with a corresponding loading coefficient of 3.4 and 3.5 , which is consistent with the theoretical calculation of $20.9 \mathrm{~m}$ as the loading distance and 3.64 as the loading coefficient. The simulation result suggests that the subsidence of the overlaying strata is the main cause of the drastic increase in the resistance on the support of the working face during the mining under the concentrated coal pillar.

(3) A dynamic loading model featured with the combinatorial key strata-the immediate roof-the support-was established. The expression of the loading coefficient during the instability of the fractured rock column was discussed based on the conservation of mechanical energy law along with the characteristics of the loading coefficient under various overlaying strata structures.

\section{Data Availability}

The data used to support the findings of this study are available from the corresponding author upon request.

\section{Conflicts of Interest}

The authors declare that they have no conflicts of interest regarding the publication of this paper.

\section{Acknowledgments}

The authors thank the National Natural Science Foundation of China for its support to this study. This study was supported by the National Natural Science Foundation of China (nos. 51774229 and 52004204), the Innovation Capacity Support Program (Science and Technology Innovation Team) of Shaanxi Province (no. 2018TD-038), the Natural Science Fundamental Research Program-Joint Fund Project of Shaanxi Province (no. 2019JLM-41), and Open Fund Project of State Key Laboratory for Water Resources Protection and Utilization in Coal Mining (no. SHJT-17-42.3).

\section{References}

[1] Z.-J. Hou, "Discussion on failure mechanism of overlying rock in coal seam under thick sand," Ground Pressure and Strata Control, vol. 12, no. 1, pp. 37-40, 1995.

[2] Z.-J. Hou, "Study on key stratum in shallow seam," Journal of China Coal Society, vol. 24, no. 4, pp. 359-363, 1999.

[3] X. I. E. Xing-Zhi, "Study on the characteristics of strata behavior in shallow seam longwall mining under the room-and-pillar mining goaf," Journal of China Coal Society, vol. 37, no. 6, pp. 898-902, 2012.

[4] P. E. N. G. Xiao-Zhan, X.-M. Cui, and L. I. Chui-Yi, "Design and practice of room \& pillar water-preserved mining for shallowly buried coal seam in north of Shaanxi Province," Journal of Mining \& Safety Engineering, vol. 25, no. 3, pp. 301-304, 2008.

[5] E.-J. Fu, Study on Reasonable Length of Mining Area and Parameter of Pillar of Nanliang Coal Mine with the Partitional Coal Mining, Xi'an University of Science and Technology, Xi'an, China, 2010.

[6] L. I. Hao-Dang, Y. A. N. G. Han-Hong, B. Zhang et al., "Control study of strong strata behaviors during the fully mechanized working face out of concentrated coal pillar in a shallow depth seam in proximity beneath a room mining goaf," Journal of China Coal Society, vol. 40, no. S1, pp. 6-11, 2015.

[7] J. U. Jin-Feng and J.-L. Xu, "Prevention measures for support crushing while mining out the upper coal pillar in close distance shallow seams," Journal of Mining \& Safety Engineering, vol. 30, no. 3, pp. 323-330, 2013.

[8] J. U. Jin-Feng, J.-L. Xu, W.-B. Zhu et al., "Mechanism of strong strata behaviors during the working face out of the upper dip coal pillar in contiguous seams," Journal of China Coal Society, vol. 35, no. 1, pp. 15-20, 2010.

[9] Z. H. U. De-Fu, Study on the Bearing Characteristics of Shallow Insufficient Collapsed Gob and Hazard Induced Mechanism in Lower Seam Mining, China Mining University, Xuzhou, China, 2018.

[10] J. Zhang, B. Wang, T. Yao et al., "Strong strata behavior in the shallow and close distance coal seam beneath room- and-pillar mining goaf," Journal of Xi'an University of Science and Technology, vol. 37, no. 6, pp. 801-806, 2017.

[11] Z.-J. Hou, "Analysis of combinatorial key strata stability in shallow coal seam with thick loose bed," Journal of China Coal Society, vol. 25, no. 2, pp. 127-131, 2000.

[12] Q. I. A. N. Ming-Gao, M. I. A. O. Xie-Xing, J.-L. Xu et al., Key Strata Theory in Ground Control, China University of mining and Technology Press, Xuzhou, China, 2000.

[13] Z.-J. Hou and J. Zhang, "Criterion of broken and limit stride calculation in shallow coal seam cooed with thick loose layer," 
Journal of Liaoning Technical University, vol. 23, no. 5, pp. 577-580, 2004.

[14] Z.-J. Hou, "Study on application of combinatorial key stratum theory and parameters determining," Journal of China Coal Society, vol. 26, no. 6, pp. 611-457, 2001.

[15] J. Wang, S. Yang, Y. Li, and Z. Wang, "A dynamic method to determine the supports capacity in longwall coal mining," International Journal of Mining, Reclamation and Environment, vol. 29, no. 4, pp. 277-288, 2015. 